\title{
Consumer Preference for Broiler Meat in Ghana: A Conjoint Analysis Approach
}

\author{
George T-M. Kwadzo ${ }^{1}$, Fidelis Dadzie ${ }^{1}$, Yaw B. Osei-Asare ${ }^{1} \&$ John K. M. Kuwornu ${ }^{1}$ \\ ${ }^{1}$ Department of Agricultural Economics and Agribusiness, University of Ghana, Legon, Ghana \\ Correspondence: John K. M. Kuwornu, Department of Agricultural Economics and Agribusiness, P. O. Box LG \\ 68, University of Ghana, Legon, Ghana. E-mail: jkuwornu@gmail.com
}

Received: December 22, 2012 Accepted: January 9, 2013 Online Published: February 28, 2013

doi:10.5539/ijms.v5n2p66 URL: http://dx.doi.org/10.5539/ijms.v5n2p66

\begin{abstract}
Understanding Consumer's preferences on attributes of broiler meat are the first step to successfully positioning the domestic poultry industry to compete effectively with import substitutes. Data was obtained from 206 consumers made up of households, food service providers and institutions using a structured questionnaire. Using conjoint analysis (CJA), this study analyzes consumers' preferences for broiler meat attributes in the Greater Accra, Tema and Kumasi Metropolis for the various categories of consumers. Though the preference of the various consumers vary, the results show that while taste, availability and proximity are important attributes, it is the price of the meat followed by the form attributes of the meat that influences the ordering of consumers' preference in purchasing broiler meat the most. The results have implications for broiler meat marketing and investment in the poultry sector in Ghana.
\end{abstract}

Keywords: consumer preference, poultry industry, poultry meat, conjoint analysis, food attributes, taste, price

\section{Introduction}

The Government of Ghana in the 1960's identified the poultry industry as having the greatest potential for addressing the acute shortfall in the supply of animal protein. The industry was also identified as having the potential for the creation of employment opportunities for the population. Commercial poultry production grew rapidly during the 1980-1990s, developing into a vibrant sector that supplied about 80 percent of available chicken meat and eggs in the country (Global agricultural Information Network, 2011). Worldwide, the poultry sub-sector is particularly a vital source for the supply of animal protein in the daily diet of the average household. With its high feed conversion efficiency, it has gained a price advantage over other types of meat and has become the meat of choice for many households (Iddamalgoda et al., 1998).

Kese (1998) indicated that there was an expansion in the number of poultry farms in Ghana in the 70's and early 80 's, adding that these investments were because of increasing disposable income of Ghanaian consumers, rapid urbanization and the awareness of the nutritional value of poultry and eggs products. Atarah (2005), reports that by 1995 , Ghana domestically supplied $95 \%$ of the total amount of poultry meat consumed, with imports accounting only for $5 \%$. However, by 2004 though trend in the consumption of poultry meat has increased substantially, $89 \%$ of the total amount of poultry meat consumed was imported, with the domestic producers only supplying $11 \%$.

The meat production sector of the poultry industry is currently perceived to be 'dying' as consumer preference has shifted towards imported substitutes due mainly to price sensitivity. To achieve Ghana government's objective of increasing the supply of meat, animal and dairy products from the then aggregate production level of $30 \%$ of domestic demand in 2007 to $80 \%$ of domestic demand by 2015 and reducing the incidence of poverty among farmers (who are also livestock keepers) from $59 \%$ to $30 \%$ by the year 2015 (MOFA, 2007), the livestock development policy among its strategies aims at: (1) Improving access to quality feed and water, and (2) Develop commercial poultry as the priority for improving meat supply in the short term, while measures are implemented to transform smallholder production into profitable enterprises.

Though commercializing the poultry industry has the potential in achieving the objective of improving meat supply, the attributes of the broiler meat that affect consumer preference must be clearly understood, so as to inform the type of investment necessary to produce broiler meat that meet domestic market requirements of those attributes that consumers value most and attract purchasing power. The rest of the paper is structured as 
follows. Section 2 provides the materials and methods; Section 3 presents the empirical results and discussions; and Section 4 presents the conclusions and recommendations.

\section{Materials and Method of Analysis}

\subsection{Study Area}

The study was carried out in two major regions in Ghana. These were the Greater Accra and Ashanti Regions. These two regions were chosen for the high urban population and for the fact that a considerable amount of the commercial poultry meat produced in the country come from those regions.

The Greater Accra Region is found on the coastal belt of Ghana. The region lies between longitudes $1^{\circ} 8^{\prime} \mathrm{E}-0^{\circ}$ $30 \mathrm{~W}$ and latitudes $5^{\circ} 70^{\prime}-6^{\circ} 8^{\prime} \mathrm{N}$ of the equator. Accra and Tema, the specific places where part of the data for the study was obtained, are located in this region. The region shares borders with Volta Region to the east, Eastern Region to its north and Central region to its west. In relation to size, it has the smallest size among the 10 regions in the country, having a total land size of 3.24 thousand square kilometres ( $1.4 \%$ of the country's total land area).

The Ashanti Region is found in the middle part of Ghana. It is located between longitudes $0^{\circ} 15^{\prime} \mathrm{W}-2^{\circ} 15^{\prime}$ and latitudes $6^{\circ} \mathrm{N}-7^{\circ} 30^{\prime} \mathrm{N}$ of the equator. The region is surrounded by four regions. To the North and North West is Brong Ahafo Region, to the South East is the Eastern Region, and to the South West are the Central Region and Western Region. The region is the third largest in the country (in terms of land area) after the Northern and Brong Ahafo Regions. It has a total land area of 24.39 thousand square kilometres (10.2\% of Ghana's total land area).

\subsection{Data Collection}

Consumer preference analysis for preferred attributes of the broiler meat was divided into two major parts. The first part included 50 respondents from which a structured questionnaire was administered to obtain information on their perception of the locally produced broiler meat against the imported substitute. A likert scale was used in the questionnaire to obtain the information. The second part covered 200 consumers; some of the respondents were involved in the first consumer survey. The full product profile method in the conjoint data collection was deployed. The simple random sampling method was used in selecting respondents included in the study. Data for assessing the viability of identified investment opportunities was taken using a discussion approach with key stakeholders in the broiler industry.

\subsection{Analytical Framework}

\subsubsection{Buyers Benchmarking Analysis}

The buyers benchmarking analysis was used to assess the domestically produced broiler meat, from the perspective of the consumer, to the imported broiler meat on some identified attributes. A survey using purposive sampling of some consumers, was used to ascertain the reasons why consumers buy the broiler meat they consume. The seven most occurring factors were used in the buyers benchmarking analysis.

Giving these factors, consumers were then made to rank the domestically produced broiler meat in relation to these factors. The imported broiler meat was used as the benchmark by which the domestically produced broiler meat was compared. A total of 50 consumers, comprising of households (25), institutions (5) and food service providers (20) were involved in comparing the domestic broiler meat against the imported broiler meat. On a scale of one to five, with one being the least and five the highest, in terms of desirability, consumers were made to rank price, taste, form of the meat, proximity and availability for both the imported and the locally produced chicken.

The decision rule in the buyers benchmarking analysis was: the higher the average rank given to a factor for either domestic or imported broiler meat, the better the satisfaction derived from that factor or attribute.

\subsubsection{Conjoint Analysis}

Conjoint analysis was used to analyze consumer preference for the attributes of the broiler meat. The reason being that, it enables trade-off between attributes to be established when multi attributes are taken together. With resource scarcity being an implicit factor in the real world, investment should be made to address those factors that matter most to the consumer. Conjoint analysis helps identify the factors that matter most to the different category of consumers that are included in the study by estimating the relative importance that each attach to a given factor in making a purchasing decision. Because the demand functions for the various categories of consumers differ, with households being driven by utility and restaurants by profit, it is expected that the relative importance that each category attached to the attributes will differ. However, despite these differences, conjoint 
analysis is able to also provide an overall relative importance that all the different categories of consumers attach to a given factor in making a purchasing decision.

The following seven steps were taken in the conjoint analysis in this study:

a) Establishing the attributes

b) Assigning attribute levels

c) Selecting the conjoint methodology

d) Deciding which profile to present to the respondents

e) Establishing preference

f) Choosing the presentation method

g) Selecting a method for part-worth estimation

\subsubsection{Factors Influencing Consumer Food Preference}

Randall and Sanjur (1981) revealed that an individual's food preference is influenced by the individual's own characteristics (i.e., age, sex, education, income nutrition etc.), the characteristics of the food (i.e., taste, appearance, texture, cost, food type, form, method of preparation etc.), and the environment (i.e., season, degree of urbanization etc.). These factors are consistent with Khan (1981) who indicated that consumer preference for food is influenced by the following: personal, socio-economic, educational, biological, physiological, psychological, extrinsic, intrinsic, cultural, religious, and locational factors. Based on these studies, we established the attributes as presented below.

\subsubsection{Establishing the Attributes}

The attributes (packaging, taste of the meat, price of $2 \mathrm{~kg}$ of the meat, form of the meat, availability of the meat and the proximity of accessing the meat) that were used in the buyers benchmarking analysis were also used in the conjoint study. Not all the attributes were used in the analysis because of some peculiar problems they presented. Packaging was dropped out of the attributes used because its inclusion resulted in unrealistic product (such as packaged live bird) which is not a normal occurrence in Ghana. Packaging was therefore removed to minimize interattribute correlation. The attributes included were: Price of $2 \mathrm{~kg}$ of the broiler meat, the form in which the broiler meat is sold, the taste of the meat, the proximity within which the meat can be accessed and the availability of the meat.

\subsubsection{Assigning Attribute Levels}

The levels chosen for each of the attributes in this study were assumed to be plausible, actionable and capable of being traded off as suggested by Pol and Ryan (1996) and communicable (Hair et al., 2006). Hair et al., (2006) suggest that to represent the respondent's judgment accurately, all attributes that create or detract the overall utility of the product must be included in the analysis. The levels of the attributes in the study are as found on the domestic market. The price of GHS 6.00 reflects the price of $2 \mathrm{~kg}$ of imported broiler bird and GHS 10.00 reflects the minimum retail price of $2 \mathrm{~kg}$ of domestic broiler bird. Table 1 shows the attributes and their related levels as used in the study.

Table 1. Attributes and their related levels

\begin{tabular}{ll}
\hline Attributes & Levels \\
\hline Price & GHS 6.00 \\
& GHS10.00 \\
Taste & Tasty \\
& Not tasty \\
Form of the Meat & Parts \\
& Dressed whole \\
Proximity & Live Bird \\
& Within 500 meters \\
Availability & Beyond 500 metres \\
& Regular \\
\hline
\end{tabular}




\subsubsection{Selecting a Conjoint Methodology}

The traditional conjoint methodology was used in the study. Because of the small number of factors, the choice-based approach could also have been used, but the absence of proposed interactions and the desire for reducing the task complexity gave the traditional method an edge over the choice-base method.

\subsubsection{Profiles Presentation}

The above set of attributes can generate 48 products that should have been presented to the consumer for evaluation. However, Kotri (2006) advices that though the best practice is to allow the respondents to rate all possible combinations, the respondent's ability to rate, when the combinations are many reduce. Hence the Fractional factorial design using the statistical package, Orthoplan, provided in SPSS 17 (SPSS, Inc., 2007), was used to reduce the product combination to 8 . The 8 products are assumed to be orthogonal. Hair et al (2006) suggest that, given a number of attributes and level, there are minimum number of stimuli that can be employed and yet have fair representation of all the factors under consideration. The minimum the study could have used is given as:

Minimum number of stimuli $=$ Total number of levels across all factors-Number of factors +1

Hence the minimum number of product combinations that could have been used is as follows (Note 1). Therefore, the fractional factorial design that gave 8 combinations is within the requirement for a conjoint analysis, given the number of factors and levels.

\subsubsection{Establishing Consumer Preference in Conjoint Analysis}

Hair et al., (2006) indicate that there are two approaches to establishing consumer preference in conjoint analysis. These approaches are the rank ordering approach and the ratings approach. This study used the rank ordering approach, where the consumers were made to rank the product combination from the most preferred to the least preferred. This approach is more reliable and provides more flexibility in estimating different types of composition rule.

\subsubsection{Choice Presentation Method}

To ensure realism and allow for the use of rankings, the study used the full profile method in obtaining respondents evaluations. The Statistical Package for Social Science (SPSS) was used to generate the combination of the profiles using the display design procedure. Table 2 shows two out of the eight profiles used in the study.

Table 2. Two representation of full product profile

\begin{tabular}{ll}
\hline $\begin{array}{c}\text { Form of the meat (Local) } \\
\text { Dressed whole }\end{array}$ & Form of the meat (Imported) \\
Parts \\
Price of 2 kg of the meat & Price of $2 \mathrm{~kg}$ of the meat \\
GHS 10.00 & GHS 6.00 \\
Taste of the meat & Taste of the meat \\
Tasty & Tasty \\
Availability of the meat & Availability of the meat \\
Seasonal & Regularly \\
Proximity & Proximity \\
Within $\mathbf{5 0 0} \mathbf{~ m}$ & Within $\mathbf{5 0 0} \mathbf{~ m}$ \\
Rank & Rank \\
\hline
\end{tabular}

\subsubsection{The Part-Worth Estimation Procedure}

The study used the linear additive model to specify the relationship between the attributes and utility, which assumes that the overall utility derived from any combination of attributes, is the sum of the separate part worth (utilities) of each level of an attribute. Emery and Barron (1979) and Pol and Ryan (1996) suggest that other models such as the interactive model rarely result in a better fit than the linear additive model. The linear model is specified as:

$$
U=\beta_{0}+\beta_{1} \text { Taste }+\beta_{2} \text { Price }+\beta_{3} \text { Form }+\beta_{4} \text { Proximity }+\beta_{5} \text { Availability }
$$


where $\mathrm{U}$ denotes utility for a profile with a given level of each attribute, $\beta_{0}, \ldots, \beta_{5}$ denotes the coefficient of the model to be estimated. Taste, Price, Form, Proximity and Availability are the attributes included in the conjoint study. The relative importance $R I_{i}$ of an attribute " $i$ " is, then, given by:

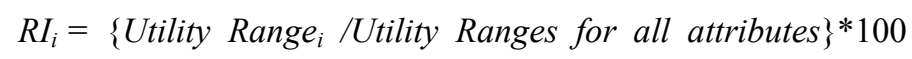

\section{Empirical Results and Discussion}

\subsection{Socio-Economic Characteristics of Respondents}

Of the 206 consumers included in the study, $16.02 \%$ were in the restaurant business, with $36.36 \%$ of the restaurant in Accra, $36.36 \%$ and $27.27 \%$ in Tema and Kumasi, respectively. Institutions (comprising of Senior High Schools and Hospitals) constituted $4.85 \%$ of the consumers interviewed, with $30 \%, 20 \%$ and $50 \%$ situated in Accra, Tema and Kumasi, respectively. About $43.69 \%$ of the consumers interviewed were households, with $33.33 \%$ of them in Accra, 33.33\% in Tema and 33.33\% in Kumasi. Fast food points and Hotels constituted $24.27 \%$ and $11.17 \%$, respectively. Of the Fast food points included in the study, $30 \%$ were in Accra, while Tema and Kumasi accounted for $20 \%$ and $50 \%$, respectively. Also, $34.78 \%$ of the Hotels included in the study were situated in Kumasi, with the number included in Accra and Tema making up 21.74\% and $43.48 \%$ respectively.

In relation to the amount of broiler meat consumed by the various categories of consumers, restaurants, hotels and fast food providers have a mean consumption of $402.2 \mathrm{~kg}$ per week in their business operation, with the modal consumption being $400 \mathrm{~kg}$ per week. The highest amount consumed was 1,690 kg per week with the least amount being $150 \mathrm{~kg}$ per week. The institutions had a mean consumption of $112 \mathrm{~kg}$ per week with a modal consumption of $110 \mathrm{~kg}$ per week. The lowest amount consumed by an institution per week was found to be $90 \mathrm{~kg}$ per week and the highest being $130 \mathrm{~kg}$ per week. Households, on average purchased $2.5 \mathrm{~kg}$ of broiler meat per week. The modal purchase was found to be $2 \mathrm{~kg}$ per week, the lowest amount purchased found to be $1 \mathrm{~kg}$ per week and the highest being $4 \mathrm{~kg}$ per week. It can therefore be inferred that, majority of the consumption of broiler meat is by the food service providers (restaurants, hotels and fast food joints), which is in line with the conclusion by Alyward (2000) who indicated that, the international growth in the demand and supply of broiler meat will be primarily driven by large fast food chains because of its increasing patronage.

\subsection{Buyers Benchmarking}

Figure 1 shows the comparison of the locally produced broiler meat and the imported broiler meat in reference to taste, pricing, packaging, proximity of access, availability and form of the output, from the customers' / consumers' perspective. The study revealed that apart from the taste attribute that the domestically produced broiler performed relatively better than its import alternative, in terms of meeting consumer satisfaction, it performs worse on all other indicators. The average of the consumers' ratings indicated that the pricing of the imported broiler meat was better than the locally produced birds. It also revealed that the form in which the imported broiler meat gets to the consumer is better than that of its local counterpart which basically comes with limited options to choose from. In relation to proximity, consumers indicated the imported broiler meat has an advantage over the local broiler meat because it is available in cold stores all around and that the imported meat is almost always available to consumers than the locally produced broiler meat which has taken a somewhat seasonal production cycle.

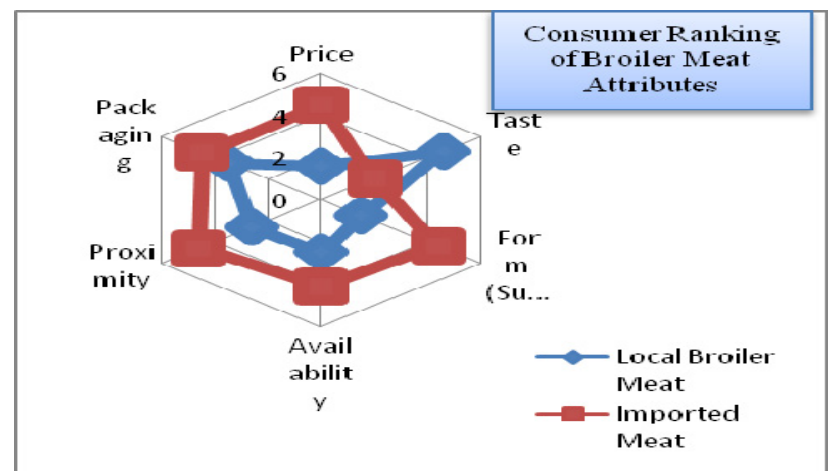

Figure 1. Consumer ranking for domestic and imported broiler meat attributes 


\subsection{Conjoint Analysis}

Conjoint analysis was used to estimate the part-worth (utility) that the consumers attach to the various levels of the attributes of the broiler meat considered in the study. The results for households reveal that the households preferred whole carcass than any other form of the broiler meat based on the higher utility estimate (Table 3). The next most preferred form of the broiler meat was in parts and the least preferred form was the live bird. This pattern is expected since the working schedule of most city consumers give them less spare time to spend on household chores, hence their high preference for easy to cook forms of the meat rather than the live form. In relation to price, it was revealed that the consumer preferred lower prices (GHS 6.00 for $2 \mathrm{~kg}$ of meat) to higher prices (GHS 10.00 for $2 \mathrm{~kg}$ of meat). This is expected if the consumer is to be assumed to be a rational consumer. The household consumers preferred tasty broiler meat to less tasty meat, regular supply to seasonal supply, having access to meat near them than it being far away (Table 3).

The result in relation to food service providers (restaurants, hotels, fast food joints) revealed that unlike households, broiler meat in parts was the most preferred. This can be explained by the nature of dishes they provide clients, which calls for the use of specific parts, hence making it irrational to go for a whole bird and having some part going waste. However, the results in Table 3 indicate that, given the choice of dressed whole carcass to live bird, the food providers preferred the dressed whole. Just like household consumers, they preferred low price, tasty, regular and easy to access forms of the meat. The preference for the institutions was the same as that of the food service providers with the exception that they attached different utility values to the various levels of the attributes as presented in Table 3. These results are consistent with the rankings of all the three categories of respondents in the sample (i.e., combined respondents of Households, Restaurants/ Hotels/Fast Food Joints, and Institutions).

Table 3. Estimated utility values (part-worth)

\begin{tabular}{llllll}
\hline Attributes & Factors & \multicolumn{3}{c}{ Utility Estimates } \\
\cline { 3 - 6 } & & Household & $\begin{array}{l}\text { Restaurant/ } \\
\text { Hotels/Fast } \\
\text { Food Joints }\end{array}$ & Institutions & All \\
\hline Form & Parts & 0.155 & 1.027 & 1.5 & \\
& Dressed whole & 0.245 & 0.727 & 1.125 & 0.54 \\
\multirow{2}{*}{ Price } & Live bird & -0.36 & -1.753 & -2.625 & -1.17 \\
\multirow{2}{*}{ Taste } & GHS 6.00 & 1.842 & 0.485 & 1.2 & 1.131 \\
\multirow{2}{*}{ Availability } & GHS 10.00 & -1.842 & -0.485 & -1.2 & -1.131 \\
& Tasty & 0.15 & 0.415 & 0.425 & 0.296 \\
Proximity & Rot Tasty & -0.15 & -0.415 & -0.425 & -0.296 \\
& Regularly & 0.5 & 1.745 & 0.675 & 1.131 \\
& Seasonal & -0.5 & -1.745 & -0.675 & -1.131 \\
& Near (within 500m) & 0.331 & 0.185 & 0.2 & 0.251 \\
\hline
\end{tabular}

Source: Field data, 2009

Table 4 shows the relative importance that the various groups of consumers attach to the attributes of the broiler meat. For households, Table 4 reveals that the price of the broiler meat is very important in making purchasing decision than the other attributes. This is followed by the form of the meat. They prefer the meat in the form of dressed whole, followed by parts than it being live bird. Availability was the next most important attribute, followed by taste, with proximity being the least important.

Table 4. Relative importance of the attributes

\begin{tabular}{|c|c|c|c|c|}
\hline \multicolumn{5}{|c|}{ Average importance Level } \\
\hline Attributes & Household & Res / Hot / FF & Institution & Joint \\
\hline Form & 29.587 & 32.389 & 45.195 & 31.769 \\
\hline Price & 42.653 & 11.44 & 26.291 & 26.228 \\
\hline Taste & 8.691 & 10.026 & 9.294 & 9.389 \\
\hline Availability & 11.519 & 41.968 & 14.85 & 26.91 \\
\hline Proximity & 7.55 & 4.176 & 4.369 & 5.704 \\
\hline
\end{tabular}

Source: Field data, 2009 
In contrast to the importance that household's attach to the various attributes, the food service providers (restaurants, hotels and fast food joints) considers availability (whether seasonal or regular) as the most important attribute by assigning $41.97 \%$. Relating this rating to Table 3, it can be seen that these categories of consumers prefer the meat on regular basis to seasonal basis; due to the high cost that stock out can bring to them in terms of lost of market. The next most important attribute was the form of the meat which had $32.39 \%$, followed by price of the meat (11.44\%), taste of the meat (10.23) and proximity $(4.18 \%)$.

With the institutions, the form of the meat (whether parts, dressed whole carcass or live) was the most important attribute $(45.20 \%)$. This was not expected since it was assumed that considering the little budget they operate on, the most important attribute should be the price of the broiler meat. However, a follow up to some of the institution revealed that, as much as price is important, they will not purchase the broiler meat no matter how low the price is, if it is not convenient for their use. Price was the next most important attribute $(26.29 \%)$ to the institution followed by availability (14.85\%), Taste (9.24\%) and Proximity (4.37\%).

Further, the data obtained from the combined respondents of Households, Restaurants/ Hotels/Fast Food Joints, and Institutions indicated that, the Form in which they desire the meat having $31.77 \%$ was the most important attribute when making their choice. This is followed by availability and price with $26.91 \%$ and $26.23 \%$, respectively. Taste $(9.39 \%)$ was the fourth most important attribute since it can be spiced to preferred taste. Proximity was the least important attribute to all the consumers.

Relating the results of the buyers benchmarking (Figure 1) with the conjoint results (Table 4) gives an insight into why consumers prefer the imported meat to the locally produced broiler meat. Though the taste of the locally produced broiler was given a higher rating than its imported counterpart in the buyers' benchmarking, the conjoint analysis revealed that consumers don't attach so much importance to taste, hence are not likely to base their purchasing decisions on taste. However, the imported broiler meat had a higher rating for the price of the meat, availability of the meat and the form of the meat in the buyers' benchmarking, which the conjoint result indicate has a high influence on the purchasing decision of the consumer in relation to the importance they attach to those attributes. Consequently, it is expected that consumers will buy more of the imported meat.

\section{Conclusions and Recommendation}

This study examines the consumer preference for broiler meat in Ghana using a conjoint analysis approach. Data was obtained from 206 consumers made up of households, food service providers and institutions using a structured questionnaire. Using conjoint analysis (CJA), this study analyzes consumers' preferences for broiler meat attributes in the Accra, Tema and Kumasi Metropolis for the various categories of consumers. Though the preference of the various consumers vary, the results show that while taste, availability and proximity are important attributes, it is the price of the meat followed by the form attributes of the meat that influences the ordering of consumers' preference.

The results of the buyers benchmarking indicated a higher average ranking for the taste of the locally produced broiler meat as compared to the imported broiler meat by the consumers. However, the consumers, in relation to pricing, availability, proximity / access and packaging of the meat, gave a higher average ranking for the imported broiler meat. This implies that for domestic broiler production to replace imports of poultry meat, cost of production must be drastically reduced through improve productivity, thereby translating into lower prices of the locally produced poultry meat. In addition, the distribution must be expanded coupled with smaller packaging to improve access, both physical and financial.

The result of the conjoint analysis revealed that, the consumers preferred processed broiler meat to live bird, desired tasty meat that is easily accessible, regularly available and low priced. However, the consumers attached more importance as a group to the form of the meat when making purchasing decisions. The next most important attribute was availability of the meat, followed by the price of the meat, the taste, with proximity being the least important attribute. The importance attached to these attributes nevertheless varies from one group of consumers to the other. It can also be concluded from the buyers benchmarking that, with the exception of the taste of locally produced broiler meat which has better attribute than its imported substitute, from the consumers' perspective, imported broiler-meat has better attributes in relation to pricing, availability, proximity / access to the meat and packaging.

The study provides the following recommendations. First, broiler meat should be processed rather than sold as live bird, since consumers attached the highest importance to the form of the meat in their purchasing decisions. 
Second, the increasing supply of domestic broiler meat at reasonable prices through productivity improvement is necessary in making the domestic meat as competitive as the imported substitute, given the result that the availability and price of the meat influenced purchasing decisions.

Third, in encouraging commercializing in the poultry sector, the Government of Ghana should provide investment and tax incentives to ensure that investment tailored to produce broiler meat meets the desired requirements of the attributes that consumers value most.

Lastly, the establishment of processing facilities through public-private partnership (PPP) should be made an integral part of the commercialization strategy in the poultry sector to meet form and price competition of imported broiler meat.

\section{References}

Atarah, L. (2005, June 14). Playing The Chicken: Ghnana Vrs the IMF. Retrieved January 16, 2009 from http:// www.corpwatch.org/article

Aylward, L. (2000). International Intrigue: Is this the golden era for U.S. exporters or just the beginning? Meat and poultry, October, 34-36.

Emery, D., \& Barron, F. (1979). Axiomatic and numerical conpoint measurement: An evaluation of diagnostic efficacy. Psychometrika, 44, 195-210. http://dx.doi.org/10.1007/BF02293971

Global Agricultural Information Network. (2011). Poultry and products brief annual. GAIN Report.

Hair, J. F., Anderson, R. E., Tatham, L. R., \& Black, W. C. (2006). Multivariate Data Analysis (5th ed.). New Jersey: Prentice-Hall PTR.

Iddamalgoda, I., Sugiyama, M., Oguri, K., Arahata, K., \& Kai, S. (1998). Present Situation and Future Prospects of Chicken Meal Production and Consumption in Asia-A Study of Nine Countries. Japan Poultry Science, 35(1), 9-18. http://dx.doi.org/10.2141/jpsa.35.9

Kese, A. G. (1988). Profitable Poultry Production. Accra: Ghana Animal Science Association.

Khan, M. A. (1981). Evaluation of selection patterns and preferences. CRC Critical Review in Food Science and Nutrition, 15(2), 129-153. http://dx.doi.org/10.1080/10408398109527314

Kotri, A. (2006). Analyzing Consumer Value Using Conjoint Analysis: The Example of a Packaging Company. Tartu: Tartu University Press.

Ministry of Food and Agriculture, MOFA. (2007). Food and Agriculture Development Policy (FASDEP II). Accra: Repiblic of Ghana.

Pol, M., \& Ryan, M. (1996). Using conjoint analysis to establish consumer preferences for fruits and vegetables. British Food Journal, 98, 5-12. http://dx.doi.org/10.1108/00070709610150879

Randall, E., \& Sanjur, D. (1981). Food preference: their conceptualization and relationship to consumption. Ecology of Food and Nutrition, 11(3), 151-161. http://dx.doi.org/10.1080/03670244.1981.9990671

SPSS, Inc. (2007). SPSS 17 for Windows. Chicago, IL, USA.

\section{Note}

Note 1. Total number of levels across all factors $=2+2+3+2+2=11$; Number of attributes $=5$; Minimum number of products combination $=11-5+1=7$. 